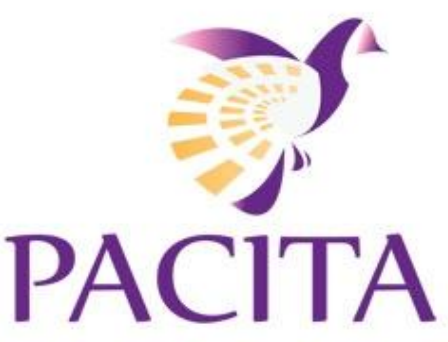

\title{
PACITA
}

Collaborative project on mobilisation and mutual learning actions in European Parliamentary Technology Assessment

Grant Agreement no. 266649

Activity acronym: PACITA

Activity full name:

Parliaments and Civil Society in Technology Assessment

\section{DELIVERABLE 5.2}

\section{Policy Brief on Public Health Genomics \\ An Agenda for the Policy Hearing on 18 Jan 2014 (Lisbon, Portuguese Parlament)}

Due date of deliverable: December 2013

Actual submission date: February 2014

Start date of Activity: 1 April 2011

Duration: 4 years

Author(s): Dirk Stemerding and André Krom (editors).

Organisation name of lead beneficiary for this deliverable: Rathenau Instituut, The Netherlands 
ChANGE RECORDS

\begin{tabular}{|l|l|l|l|}
\hline Version & Date & $\ldots \ldots \ldots \ldots \ldots \ldots \ldots \ldots \ldots \ldots \ldots \ldots \ldots \ldots \ldots \ldots \ldots \ldots \ldots \ldots \ldots \ldots \ldots \ldots \ldots \ldots \ldots \ldots \ldots \ldots \ldots \ldots \ldots \ldots \ldots \ldots \ldots \ldots \ldots$ & Author \\
\hline & & & \\
\hline & & & \\
\hline & & & \\
\hline & & & \\
\hline & & & \\
\hline & & & \\
\hline & & & \\
\hline
\end{tabular}


PACITA Partners

Teknologirådet - Danish Board of Technology (DBT)

Toldbodgade 12, DK-1253 Copenhagen, Denmark,

Contact: Anders Jacobi

aj@tekno.dk

www.tekno.dk

Karlsruhe Institute of Technology (KIT)

Kaiserstr. 12, 76131 Karlsruhe, Germany

Contact: Leonhard Hennen

leonhard.hennen@kit.edu

www.kit.edu

Rathenau Insituut (KNAW-RI)

Postbus 95366, 2509 CJ Den Haag, the Netherlands

Contact: Geert Munnichs

pacita@rathenau.nl/g.munnichs@rathenau.nl

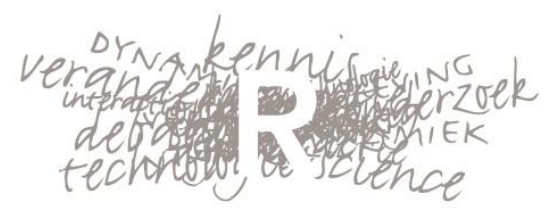

Rathenau Instituut

www.rathenau.nl

Teknologiraadet - Norwegian Board of Technology (NBT)

Prinsens Gate 18, 0152 Oslo, Norway

Contact: Christine Hafskjold

Christine.hafskjold@teknologiradet.no

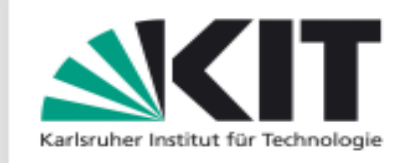

Karlsruher Institut für Technologie

\section{Rathenau Instituut}

www.teknologiraadet.no

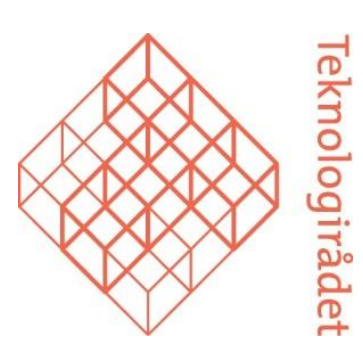


The Institute of Technology Assessment (OEAW/ITA)

Address: Strohgasse 45/5, A-1030 Vienna

Contact: Pacita-ITA team

pacita.ita@oeaw.ac.at

www.oeaw.ac.at

Applied Research and Communications Fund (ARC Fund)

5 Alexander Zhendov str., 1113 Sofia, Bulgaria

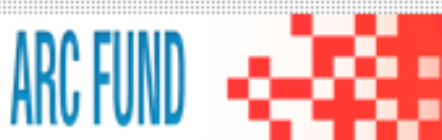

Contact: Zoya Damianova

zoya.damianova@online.bg

www.arcfund.net

Instituto de Tecnologia Química e Biológica- Institute of Technology of biology and chemistry (ITQB)

Avenida da Republica, Estacao Agronomica Nacional,

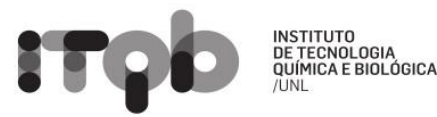

Oeiras, 2784-505, Portugal

Contact: Mara Almeida

marasilvalmeida@gmail.com

www.itgb.unl.pt/

Institute Society and Technology (IST)

Leuvenseweg 86, B-1011 Brussels, Belgium

Contact: Johan Evers

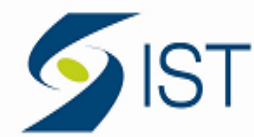

Instituut Samenleving \& Technologie

johan.evers@vlaamsparlement.be

www.samenlevingentechnologie.be 
The Catalan Foundation for Research and Innovation (FCRI)

Pg. Lluís Companys, 23, ES-08010 Barcelona, Spain

Contact: Belén López

belen.lopez@fundaciorecerca.cat

Swiss Centre for Technology Assessment (TA-SWISS)

Brunngasse 36, CH-3011 Berne, Switzerland

Contact: Danielle Bütschi

danielle.buetschi@ta-swiss.ch

www.ta-swiss.ch

Association Knowledge Economy Forum (KEF)

Galvydzio 5/96, LT-08236, Vilnius, Lithuania

Contact: Edgaras Leichteris

edgaras@zef.It

www.zef.It

\section{Technology Centre ASCR}

Ve Struhach 27, 16000 Prague 6

Contact: Lenka Hebakova

hebakova@tc.cz

www.tc.cz

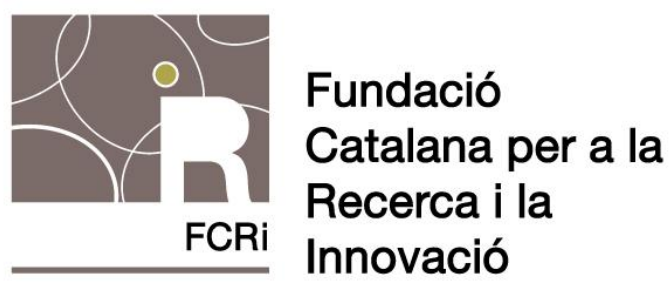

Zentrum für Technologiefolgen-Abschätzung Centre d'évaluation des choix technologiques Centro per la valutazione delle scelte tecnologiche Centre for Technology Assessment SWISS

\section{KNOWLEDGE ECONOMY FORUM}


Scientific and Public Involvement in Risk Allocations Laboratory (SPIRAL)

Boulevard du Rectorat 7/29, B31, 4000 Liège, Belgium

Contact: Pierre Delvenne

pierre.delvenne@ulg.ac.be

www.spiral.ulg.ac.be/

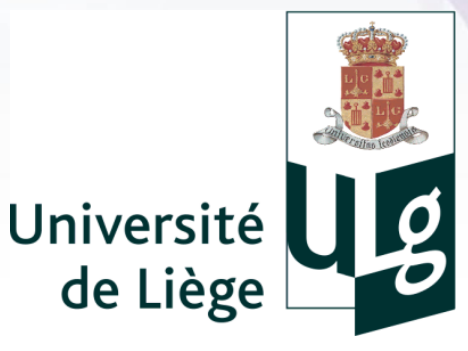

University College Cork (UCC)

Western Road, Cork, Ireland

Contact: Frederic adam

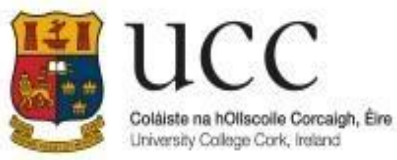

PACITA@ucc.ie

$\underline{\text { www.ucc.ie }}$

Secretariat of the Hungarian Academy of Sciences (HAS-SEC)

Nádor utca 7, H-1051 Budapest, Hungary

Contact: Janka GAUGECZ

gaugecz.janka@office.mta.hu

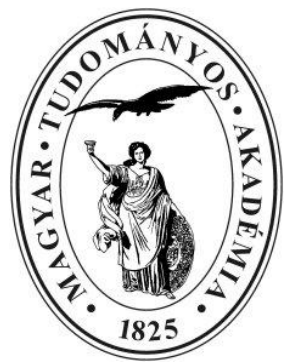

www.mta.hu 
Legal notice:

The information in this document is provided as is and no guarantee or warranty is given that the information is fit for any particular purpose. The user thereof uses the information at its sole risk and liability. Neither the European Commission nor any person acting on behalf of the Commission is responsible for the use that might be made of the following information.

(C) EPTA-PACITA 2014. Reproduction is authorised provided the source is acknowledged. 


\section{INTRODUCTION}

The aim of public health genomics is defined as the 'responsible and effective translation' of genomic information and technologies for the benefit of population health. This Policy Brief sets the agenda for the PACITA Policy Hearing on Public Health Genomics to be held on 18 Jan 2014 in the Portuguese Parliament. The Brief aims to contribute to setting a European policy agenda for the future of public health genomics, by presenting:

- Some of the most pressing policy issues concerning public health genomics

- Policy options by which these issues could be addressed

The Hearing is organized in collaboration with the PACITA Future Panel on Public Health Genomics consisting of parliamentarians from several EU member states and the European Parliament:

- Mrs. Maria De Belém Roseira (MP, Partido Socialista, Portugal)

- Mrs. Yvonne Gilli (MP, Grüne Partei der Schweiz, Switzerland)

- Mr. Jens Henrik Thulesen Dahl (MP, Dansk Folkeparti, Denmark)

- Mr. Vittorio Prodi (MEP, Group of the Progressive Alliance of Socialists and Democrats/ Partito Democratico, Italy/ STOA panel/ ENVI committee)

The Future Panel, which has been involved throughout the project, played a pivotal role in identifying issues that would require further research, deliberation, and political action. The contents of this Policy Brief are based on the work of four Expert Working Groups that have examined a range of issues that were identified by the Future Panel and have discussed potential policy options.

During the Policy Hearing, the Future Panel will discuss policy issues and options related to public health genomics with international experts, policymakers and stakeholders. Topics covered by this Brief are grouped in three main parts:

I. Issues related to developments in medical genomics research

- Data sharing and intellectual property

- 'Big data' security and privacy

- Quality Assessment

II. From research to clinical practice: current issues and future challenges

- What to screen for and when?

- Patients' rights and professional responsibilities

- Informed consent and service provision

III. Governance in public health genomics

The starting point for the discussion of specific policy issues and options in this Brief are the questions and concerns raised at the outset of the project by the Future Panel. Appendix 1 gives a brief overview of relevant legislation and guidelines as an aid to understanding the current European policymaking context in the field of public health genomics. 


\title{
I. DeVelopments in MEDical genOMics ReSEARCH
}

\author{
DATA SHARING AND INTELLECTUAL PROPERTY
}

Issues raised by the Future Panel

- Where to put the money for research (how to set priorities)?

- How to integrate genomic knowledge with knowledge of lifestyle and environmental factors?

- What business and governance models are needed to cope with increasing costs of research and innovation in the genomics area?

- What is the legal status of genetic information?

Most variation in our DNA has not yet been investigated and we cannot yet assign potential consequences to this variation for individual health and disease. In order to establish such relationships, it would be necessary to combine clinical and genomic data from large numbers of individuals. Emerging practices of Public Health Genomics (PHG) thus depend on increasing the quantity of data travelling between research and patient care whereby data collected for medical purposes are shared for research purposes and statistical analysis.

- Data sharing is considered a key policy issue in medical genomics research. However, the extent to which this will deliver health benefits is a matter of debate, which is also relevant to decisions about research priorities and resources for large-scale data collection and sharing.

The challenge of data collection in medical genomics research is already beginning to be met by a series of biobanks throughout Europe. However, databases of genomic variation and tools to examine genomic sequence data are still fragmented and not harmonized.

- This raises the question as to what extent there is a need to further consolidate and expand this infrastructure into an interoperable European network, enabling the storage, analysis and integration of massive amounts of digitalized personal medical data, including contextual information on environmental variables, lifestyle, nutrition, etc.

There is also a global dimension to sharing data and samples. New funding mechanisms such as public private partnerships (PPP) and joint ventures between pharmaceutical and informatics companies and major charitable funders are becoming increasingly common. This evolution creates new demands for data sharing arrangements that are capable of crossing national and regional boundaries.

- Legislation governing data exchange across national and regional borders is not currently in place. Considerable differences exist even among countries of the European Union who have signed the data protection directive.

Questions concerning intellectual property (IP) and patents for genes, how it is decided what is worth patent protection, and what should be publicly available for use, might be considered closed in the EU. However, the diminishing cost of whole genome sequencing and the developments of tests incorporating information on many different genetic markers deserve a 'reopening of the box'. In emerging practices of PHG, sharing and applying whole genome data will be made immeasurably more complex if it is burdened by thickets of patents each claiming ownership of discrete elements of the genome. This will inevitably push up costs and impede the introduction of innovative applications of genomic knowledge and technologies in the health care system to the potential detriment of patients and to health care systems. 
- It is time for a fresh look in Europe at the way in which IP is generated, and the use that can be made of various IP tools such as patent pools, copyrighting and open source licensing to serve a range of societal and economic benefits.

\section{Policy options}

1. Closely monitor the current development of databases of human genome variations and international networks as a basis for informed decision-making about funding and research priorities.

2. Depending on the need for data sharing, consider options for a European harmonization initiative aiming at shared standards and nomenclature as has previously been established for the quality standards of genetic testing services in Europe.

3. Support the development of an appropriate ethical and governance framework for data sharing across the EU and with other emerging players in e.g. China, India, and Latin America.

4. Rethink the current IP regime in order to avoid it becoming an obstacle to innovation and making (public) health care prohibitively expensive. Policy options include:

a. Making the IP regime more flexible, while acknowledging that a too flexible regime might undermine European competitiveness.

b. Making clear what actually falls under the scope of current patenting regime and what does not.

c. Making better use of options for compulsory licensing. 


\section{Issues raised by the Future Panel}

How to manage data in order to protect people?

A new 'big data environment' is emerging from developments in medical genomics. Expectedly, genomics data will more and more become part of individual clinical records, potentially containing information on health aspects that might affect current or future life.

In endeavouring to balance respect for privacy and enable research, current debates focus on the elaboration of data sharing policies and the limits of anonymization or de-identification. A major policy debate currently taking place in the EU is the development of the new Data Protection Regulation and the extent to which this should reduce or increase an individual's control over their health data and electronic medical records. Advocates of 'big data' (including many commercial actors) argue that current data protection legislation should be weakened to allow data mining of pseudo-anonymized health data and perhaps to exempt not only fully anonymized, but also pseudo-anonymized data from data protection and informed consent requirements altogether.

However, many studies show that medical data cannot be effectively anonymized, especially once whole genomes are included. Even if healthcare and research infrastructures build robust strategies to provide maximum privacy protection, new privacy risks are developing with the increased availability of DNA ancestry and genealogical tests. Storage of genomes linked to other data may also allow third parties to track individuals and their relatives.

- A main challenge is how to foster in Europe the development of an appropriate ethical framework that protects research participants and sample donors and allows for safe and secure data access for researchers, participants, donors and the public.

\section{Policy options}

1. While an open access policy to sharing genomics data would create ample opportunities for data mining, and for learning about the relation between genes and the environment, unlimited data travelling between research and the clinic may be considered problematic, especially when it becomes mixed up in public-private collaborations. Well-defined governance arrangements for data sharing might include:

a. Either: Restricting data sharing only to the public sphere;

b. Or: establishing clear criteria for data sharing in public-private collaborations.

2. As whole genome sequencing data cannot be effectively anonymized, current revision of the Data Protection Regulation in the EU should take into account possibilities to:
a. Create special forms of data protection for genomic data;
b. Limit genomic data storage in terms of scope and time (whereas indefinite storage without consent is a breach of the Human Rights convention);
c. Store genomic data in secured data bases that can only be accessed by people who are permitted to do so on the basis of well-defined criteria.




\section{QUALITY ASSESSMENT}

\section{Issues raised by the Future Panel}

- How to avoid hypes, how to discern hype from reality?

- How to define the validity and reliability of tests?

DNA-sequencing technologies are rapidly becoming cheaper and faster. It is envisioned that we will soon be able to get a full human sequence within a day and for less than $€ 1,000$. Reduced sequencing costs are expected to stimulate the analysis of genomes of people with diseases as well as the analysis of healthy genomes. Some experts expect that this will ultimately give us the tools to understand individual genomes and to accurately predict their consequences, thus allowing for detailed risk profiling and yielding greatly improved health outcomes. Thus far, these promises have not been fulfilled. Opinions differ on the extent to which they will be realized in future.

- A major challenge is that there is a wide gap between the ability to generate 'more data for less money', on the one hand, and the lack of understanding and validation of the clinical utility of these data, on the other .

- Without robust databases that allow for an evidence-based/informed interpretation of normal and pathogenic genomic variants, there is a clear threat that a premature technology and market driven application of next generation sequencing (NGS) in clinical practice, will inundate physicians and patients with meaningless and/or uninterpretable data.

There is substantial agreement about the criteria that are considered of key importance for the evaluation of genetic tests. Analytical and clinical validity refer to the diagnostic or predictive power of a test. Clinical utility refers to the usefulness of the test information to medical practice and to the individual receiving this information. A whole genome sequencing (WGS) test can be used to inform an individual about a great variety of health risks. To establish the clinical performance and usefulness of a WGS test numerous assessments are needed involving different studies and study populations.

- For the accumulation of evidence, multiple smaller studies tailored to the intended applications will have more value than one analysis using data from a large, generalized biobank.

The quality of genomic testing also strongly depends on the quality of the public and commercial laboratory and clinical services through which tests are provided. However, there are notable shortcomings in the current level of genetic service provision in Europe and in the context of emerging practices of PHG new challenges will arise for the organization and quality of service provision. It has been shown in a recent study that the quality of genetic testing varies widely between European laboratories. Few countries explicitly regulate genetic testing and counselling and quality assessment in clinical services is still developing. Publicly funded projects such as Eurogentest have developed quality assurance procedures for evaluating genetic testing laboratories, but these standards are voluntary.

The European Commission funded The Public Health Genomics European Network (PHGEN II) project to develop European Best Practice Guidelines for Quality Assurance, Provision and Use of Genome-based Information and Technologies In 2012 a summary of the proposed 'European Best Practice Guidelines' was endorsed in a Declaration of Rome. 
- An important policy issue is that there is a funding gap in the health care system. Research funding is available to develop genomic knowledge and technologies, but is more difficult to find for the translational studies needed to establish the clinical validity and utility of tests.

\section{Policy options}

1. Support the development and implementation of guidelines for quality assessment that are relevant for genome-wide sequencing tests, and which include assessments of the value of unsolicited findings.

2. Invest in well-designed studies in populations that are representative for the intended health care applications of genome-wide sequencing tests.

3. Make participation in quality assessment schemes mandatory for genetic testing laboratories.

4. Support the development of quality assessment schemes for genome-wide commercial tests, including assessment of clinical utility. 


\title{
II. FROM GENOMICS RESEARCH TO CLINICAL PRACTICE
}

\author{
WHAT TO SCREEN FOR AND WHEN?
}

\section{Issues raised by the Future Panel}

- What will the impact of genetics be on the health and health care experience of individuals?

- How far do we go in collecting and interpreting information?

- Right-(not)-to-know

Genomic tests are already used in a clinical context, especially for postnatal diagnosis in children with congenital disabilities and/or mental retardation, and prenatal diagnosis of fetal abnormalities observed during ultrasound. As available DNA-sequencing technologies are rapidly becoming cheaper and faster, it may become routine to sequence genes or even whole genomes of individuals for both diagnostic and screening purposes. Options for the introduction of whole genome sequencing in more or less widely established programs for reproductive and newborn screening are currently being considered and debated in the context of research, raising difficult questions of what and when to screen for.

Recessive mutations can be identified in future parents through genetic carrier screening, thus allowing them to make informed reproductive choices which may prevent the birth of an affected child. In this context genome-wide screening might be applied in a targeted way, thus offering future parents the opportunity of screening for a range of relatively frequent as well as more rare recessive conditions.

Pre-implantation genetic screening (PGS) is being performed with the aim of improving the outcome of IVF procedures. Genome-wide screening of a pre-implantation embryo might provide more comprehensive information about chromosomal defects and single gene disorders that may be helpful in selecting embryos with a good chance of implantation after IVF.

Non-invasive prenatal testing (NIPT) is based on the analysis of cell free fetal DNA present in the maternal circulation and being discussed at the moment as a replacement for established forms of prenatal screening. As soon as NIPT becomes widely available in a setting of routinely offered prenatal screening, it may also create future opportunities for the introduction of genome-wide forms of screening for a variety of conditions in the unborn child.

Newborn screening (NBS) programs in the EU currently aim to identify 1 to 30 treatable conditions. Genome-wide screening for a broader range of conditions could be envisaged. If indeed a switch were to be made to genome-wide screening in NBS programs, one could think of the possibility of keeping the whole genome sequence of the newborn for future use later in life for dealing with specific questions relating to individual health or reproductive risks.

- One of the core ethical questions in this context is whether genomic data ease the burden of decision making in the context of reproduction or, on the contrary, exacerbate it. Most likely, the latter will be the case due to the growing amount of information that needs to be taken into consideration and weighed.

- An important issue to consider in a reproductive and newborn screening context is the right of parents to make far-reaching decisions about full genome analysis for children without knowing the possible benefits of such an analysis at the time taken.

The introduction of genome-wide sequencing tests may also be envisaged in the context of public health screening programs, like cancer screening. DNA sequencing tools are already 
used today for the genetic profiling of tumours as a basis for more personalized treatments of cancer. In addition to these diagnostic applications, sequencing tests may be considered as a possible tool in developing stratified screening strategies for breast, colorectal and prostate cancer, based on multiple genetic risk factors. Such risk profiling strategies could potentially improve the efficiency of current and future screening programs and reduce their adverse consequences, although further research is needed to establish whether this is in fact the case.

\section{Policy options}

1. Reproductive and newborn screening can take the form of nationally organized public programs, but may also be initiated by private parties on a commercial basis. A clear and guiding role of public health authorities in organizing and evaluating screening could be considered as an important condition for a careful introduction of genome-wide screening tools.

2. Defining the scope of genome-wide reproductive and new-born screening can be seen as the responsibility of public health authorities, but it can also be left to decisions made by individual parents-to-be. In genome-wide carrier and prenatal screening, the aim of reproductive choice might be best served by a well-defined and limited screening offer, potentially in combination with an 'opt-in' for parents who would like to have a broader test. Genome-wide newborn screening might be restricted from a public health point of view to information that is actionable and of clinical utility for the child. The right of the child to an 'open future' is another important consideration in defining the scope of genome-wide screening.

3. In performing genome-wide screening, one option might be to carry out whole genome sequencing at birth in the context of newborn screening and to store these data for later use. Another option is to use genome sequencing only for specific purposes and only at times when it is indicated by a clear public health or individual benefit. Important issues to consider in this context are the implications of massive individual genomic data storage in terms of the infrastructure needed and questions relating to consent, privacy and access.

4. Professionals might be entrusted with the obligation to report to individuals, in the context of whole genome sequencing, findings indicating a high risk for breast or colorectal cancer.

5. Possibilities might be considered for more stratified strategies for breast and colorectal cancer screening, informed by genome-wide testing of individual genetic risk factors. An important condition is the existence of well-established national programs for cancer screening and their continual monitoring and (re)assessment. 


\section{PATIENTS' RIGHTS AND PROFESSIONAL RESPONSIBILITIES}

\section{Issues raised by the Future Panel}

- How to balance individual and collective choices and benefits?

- Right-to-know

- How should the liabilities of various stakeholders be defined in case health decisions are taken that turn out to be wrong?

In emerging practices of PHG we should distinguish between two purposes for the storage of genomics data. First, the storage of aggregated and anonymized data from many individuals in order to generate new genome-based knowledge of possible future value for the community and the individual. Secondly, the storage of an individual's genomic data in order to prevent or manage disease on a personal basis. These two different purposes imply a tension between collective needs at the level of research - widely sharing genome-based information as a basis for data integration - and the needs of the individual - only receiving specific genome-based information for specific purposes.

- Research and patient care are shaped by different interests, objectives, duties, and rules. If procedures are set out which allow transfer of data from one context into the other they should pay attention to the specific rules which guide and guard the different domains.

- Since with genomics based research the boundary between biomedical research and medical care becomes more and more permeable there is a need for harmonization of legislation governing the two domains.

Another issue relating to data storage concerns the potential feed-back to individuals and their families of research findings produced by (re-)analysis and interpretation of sequence data that have been retrieved from a biobank to which these individuals have donated.

- How should the rights and duties of researchers, clinicians and individuals in relation to the validation and feedback of results and the potential implications for an individual's care be defined and organized?

Whole genome sequence data that are generated for a specific medical purpose in a clinical or research context may reveal unsolicited findings. In emerging practices of PHG, professionals, institutional review boards, patients and their families will increasingly have to face the question of how to deal with these unsolicited findings. In this context, it is important to distinguish between the analytic device which is used for a test (which could be whole genome sequencing or an array) and the specification of the sequences or genes which have to be analysed for a given purpose.

- If analysis of only some genes or sequences is needed in order to answer a clinical question, the other parts of the genome should not be analysed (interpreted) in order not to create information which may not be validated or unsolicited findings.

\section{Policy options}

1. The tension between collective and individual interests in emerging practices of PHG might be bridged by a future infrastructure for processing, storing and maintaining genomic sequencing data in individual health records which, on the one hand, limits access to only the genomic information that is needed for clinical use at any one time and, on the other hand, retains all available data for research and for clinical use in future evaluations. 
2. Dealing with increasingly comprehensive and complex genome-wide sequencing data in a clinical context might entail:

a. The responsibility of the profession to clearly define which data are clinically actionable or of potential relevance for a patient and/or sample donor (including family members).

b. Clarification of what the individual 'right to know' implies in terms of access to sequencing data: raw data, interpreted data or only clinically actionable data?

c. Clarification of the professional 'duty to feedback' of data by making this duty dependent on the clinical or personal relevance of data for the individual and/or family members.

d. Giving people a say about whether or not research findings will be fed back to them in the future.

3. Dealing with unsolicited data might involve the following strategies:

a. The development of targeted approaches in genome-wide testing by using filters to limit the amount of data and information generated to a particular clinical purpose.

b. Seeking informed consent for the reporting of unsolicited findings.

c. Defining a list of unsolicited findings that should be reported to individuals in the context of genome-wide testing (as recommended by the American College of Medical Genetics and Genomics). 


\section{Issues raised by the Future Panel}

- Right-to-know

- How should medical services be adapted to act as a legitimate interface between producers and consumers of genetic tests?

- How to make sure that both medical professionals and citizens obtain a sufficient level of literacy to make adequate health care decisions based on genetic/genomic information?

- How to regulate direct-to-consumer markets?

Debates about how much information should be provided to individuals in the context of medical genomics research and emerging clinical practices of whole genome sequencing, revolve around the importance and meaning of informed consent as a fundamental patient right, which is tightly connected to the doctor-patient relationship.

In the context of research, data storage in large-scale biobanks poses challenges to traditional informed consent because data may be shared with large numbers of researchers, including commercial companies, both nationally and internationally, for purposes that may be unclear when the data sets are collected. Concepts such as 'presumed' consent and 'broad' consent have been introduced to fit the paradigm of data-driven research. Under a model of broad consent, individual participants delegate their decisions on what research is ethical or in the public interest to third parties or ethics committees. The concept of presumed consent implies an 'opt-out' approach to medical research in which data can be widely shared without the individual's knowledge or consent.

Options for presumed or broad consent to the indefinite storage and widespread sharing of genomics data for research seem difficult to reconcile with existing rulings for biometric databases, which imply that consent cannot be obtained freely through mandatory acceptance of general terms and conditions, or through opt-out possibilities.

- Finding acceptable and workable approaches to informed consent can be seen as a major challenge for current 'big data' research in medical genomics and the future of PHG.

In the context of emerging clinical practices of PHG, designing procedures for informed consent may also become a highly demanding task given the wide range of findings from whole-genome sequencing. With advancing technology and the ability to screen individuals for dozens or even hundreds of conditions in a single analysis, the notion of an 'effective and affordable intervention' might have to be reconsidered. The question that both health care providers and their clients will have to face in this context is not what should be tested, but rather what should not be tested.

A crucial issue in this context is the quality of health service provision. Improved understanding of the genetic basis for common, complex conditions including cancer, heart disease and diabetes, as well as advances in testing of genomic biomarkers, will increase the relevance of genetic services for the general population. Moreover, in this scenario, the role of the physician may be radically different: i.e. to provide guidance, wisdom, experience and critical appraisal of information compiled by patients themselves from a wealth of web-based clinical and genomic information. Several models have been proposed for the development and implementation of new innovative modes of genomic services provision.

However, in all countries, non-specialist health professionals are ill prepared to take advantage of genetic/genomic knowledge and lack the necessary skills to make effective use of the new technologies in their practice. Therefore, it can be expected that the prospect of effective and 
responsible translation of genome-based information and technologies into health care will be severely hampered by the availability of only a small number of health professionals with expertise in genetics.

- There is an urgent need to carefully consider the scope of education and training needs in genomic medicine, tailored to the specific work of each speciality and of primary care providers

The lack of genetic counselling is a major concern also with regard to commercial services which offer direct-to-consumer (DTC) testing on the internet for genetic variants associated with common diseases. The marketing of these tests is generally seen as a premature development. The European Commission has recently published a new draft for a revised in vitro diagnostic medical device (IVD) regulation which proposes a ban on DTC marketing of genetic tests and requires the involvement of genetic counsellors.

- Stricter regulation might indeed be needed to protect the consumer, control societal health care costs and allow commercial DNA testing at the same time.

\section{Policy options}

1. Stimulate empirical research among potential sample donors to find out whether there is large support for either specific, broad of presumed informed consent.

2. Research, clinical care and screening - in different public or private contexts - may require different procedures for informed consent, which could either:

a. be left to professionals to decide, or

b. be decided in a public discussion engaging patient and lay communities, or

c. be regulated by law.

3. The status of counselling in the health care system could be strengthened by:

a. The establishment of clinical genetics as a profession in every country;

b. Special provisions for the reimbursement of counselling costs;

c. Ratification of the Oviedo Convention on Human Rights and Biomedicine (Council of Europe) by every European country;

d. Reconsideration of the existing Council of Europe protocol on genetic counselling in view of developments in medical genomics and future practices of PHG.

4. Stimulate multi-disciplinary collaboration between geneticists and other medical specialists as well as the integration of genetic services directly into primary care.

5. Include in the current revision of the IVD regulation clinical utility data as a requirement for the quality assessment of genetic/genomic tests.

6. The European Commission might push for international regulation of DTC genetic/genomic tests. 


\section{GOVERNANCE IN PUBLIC HEALTH GENOMICS}

\section{Issues raised by the Future Panel}

- How will health costs evolve due to developments in genomics and increased use of applications?

- How to balance individual and collective choices and benefits?

- What business and governance models are needed to cope with increasing costs of research and innovation in the genomics area?

According to the aims of PHG, the introduction of genomic information and technologies should be guided by criteria that assure a process of responsible and effective translation of medical genomics research and innovation into a variety of health care settings. Although it is generally expected that whole genome sequencing will become increasingly accessible to health care providers and consumers due to its decreasing price, the downstream costs of genome-wide tests might largely outweigh the cost of the sequencing, due to the large amount of information generated and the cost of analysis, the cost of counselling, the cost of false positives and negatives (and their medical consequences), etc. In the absence of political 'intervention' genomic information and technologies will somehow find their way into the public health landscape, and may not just be beneficial but can potentially have detrimental consequences as well.

- It is important that the availability of genomic tests in (public) health care practices is based on an appropriate evaluation of their clinical utility, and not only on the basis of technological availability.

Governments have traditionally had an important responsibility for protecting/promoting public health. Public health is 'public' in the sense that it refers to the health of a population, but it also entails 'public' ways of protecting/promoting the health of a population; it stimulates programmes in which many individuals cooperate to produce goods that are not just private goods but public goods that could benefit everyone. Producing such goods requires a programmatic approach, specifically a certain level of coordination guided by collective values such as 'public health'. Part of the responsibility of governments is to formulate standards for such programmes.

- A pressing issue in this respect is whether the need for a programmatic approach in public health sets limits to introducing genomic information and technologies via other institutional arrangements, such as direct-to-consumer testing.

Many individuals and patients have participated or are currently participating in genome sequencing projects worldwide. Researchers and physicians have a special collective obligation and responsibility to ensure the safety of this public trust. Finding a balanced approach that respects and protects autonomous decision-making, confidentiality and privacy and acknowledges family and community interests, may require the engagement of key stakeholders in order to develop informed recommendations for how to integrate the new technologies for both the benefit of the individual patient and family/community/society.

In order to help health care policy makers, health care providers and other relevant stakeholders to make informed - and country specific - decisions for the application of genomic information and technologies in (public) health care and to allocate adequate resources, the role of health technology assessment is vital. Health Technology Assessment (HTA) can be defined as a multidisciplinary process that summarises information about the medical, social, organizational, economic and ethical issues related to the use of a health 
technology in a systematic, transparent, unbiased and robust manner. Its aim is to inform the formulation of safe and effective health policies that are patient focused and based on existing evaluation methods and best practices for clinical utility.

- However, HTA is not spread all over Europe. Some countries lack the expertise, while in others it is only supported by academia and not embedded in decision-making on health care provision.

The need for homogeneous quality assessment processes in EU countries has been pointed out in several recently published documents and directives (Directive 2011/24/EU) and there are initiatives in place to establish a permanent network on HTA in Europe (EUnetHTA). The implementation of a network at the pan-European level and the establishment of HTA national/local initiatives will reduce the likelihood of introducing genomic technologies that do not comply with established quality criteria and the organizational, economic and managerial capacity to provide these services.

\section{Policy options}

1. A programmatic approach in the field of PHG could be supported by organizing pilot experiments in different contexts and countries as a basis for learning about opportunities and implications.

2. Engage in this context of experimentation, assessment and decision-making relevant stakeholders, including patient advocating groups and civil groups concerned with issues raised by whole genome sequencing.

3. In this context it could also be considered how to support HTA practices that are required for the assessment of clinical validity and utility of genomic information and technologies in agreement with established best practices and context based affordability along Europe. 


\section{EDITORS}

Dirk Stemerding \& André Krom (Rathenau Instituut, The Hague, The Netherlands) January 2013

\section{SOURCES}

Future Panel on Public Health Genomics. Expert Working Group Reports, PACITA, August 2013

Expert Paper for the Future Panel on Public Health Genomics, PACITA, November 2013 


\section{APPENDIX 1}

\section{RELEVANT EU HEALTH POLICY AND FINANCING INSTRUMENTS}

The role of Health related issues as part of the Europe 2020 policy framework has been established by the Commission staff working document "Investing in Health" (2013). The document has identified several areas where structural reforms in Member States can be improved. Some of those are tightly connected with the opportunities provided by public health genomics: the need for better targeted, individualized services and benefits; improving data collection; using health technology assessment (HTA) more systematically for decisionmaking processes; improving cost-efficiency through sound innovation and smart spending; the focus of the European Innovation Partnership (EIP) on all areas of person's life (prevention, screening and early diagnosis; care and cure; active aging and independent living).

Financing instruments. A political agreement on the outstanding issues (budget, governance, co-financing) for the Third Multiannual Health Program for the $2014-2020^{2}$ has been reached in early November 2013. It is expected that new Health Program with the budget of $€ 449.394$ million will be adopted in Spring 2014. It will focus on the following areas: good practices for prevention, early detection and management of chronic diseases; health information and knowledge system; health security initiative; improvement of risk assessment by providing additional capacities for scientific expertise and mapping existing assessments; support for capacity building and cooperation with neighbouring countries; up-take of health innovations and e-health solutions; legislation relating to medical devices, medicinal products, patients' rights and cross-border healthcare; legislation on human tissues and cells; European Reference Network; databases and registries; rare diseases; patient safety.

\section{RELEVANT EU DIRECTIVES}

\section{Directive 2011/24/EU on patients' rights in cross-border healthcare ${ }^{3}$}

Elaborates on systematic and continuous efforts that should be made to ensure that quality and safety standards are improved in line with the European Council conclusions and are taking into account advances in international medical science and generally recognized good medical practices as well as taking into account new health technologies (Recital 22). Talks about interoperability of ICT systems - the problem which is entirely within a national competence (Recital 56). Calls for continued Union support in the area of cooperation in evaluation of new health technologies and provision of better evidence base for optimal use of those technologies to ensure safe, high-quality and efficient healthcare (Recital 58). In the context applicable to the Public Health Genomics the Directive suggests that further exploration of innovations in medical science and health technologies can be made by the use of European Reference Networks (Article 12), cooperation in the field of rare diseases (Article 13) and Health Technology Assessment (Article 15). And also that Member States shall ensure the establishment of National Contact Points (Article 6) which shall provide relevant

\footnotetext{
${ }^{1}$ http://ec.europa.eu/health/strategy/docs/swd_investing_in_health.pdf

2 http://ec.europa.eu/health/programme/docs/healthpgm_pres_nov2013_en.pdf

${ }^{3}$ http://eur-lex.europa.eu/LexUriServ/LexUriServ.do?uri=0J:L:2011:088:0045:0065:EN:PDF
} 
information about standards and guidelines on quality and safety.

Directive 95/46/EC on the protection of individuals with regard to the processing of personal data and on the free movement of such data ${ }^{4}$ and General Data Protection Regulation $\left(\right.$ GDPR) ${ }^{5}$

The directive 95/46/EC currently applies to the processing of personal data wholly or partly by automatic means, and to the processing otherwise than by automatic means of personal data which form part of a filing system or are intended to form part of a filing system. The directive is outdated, does not meet new globalization and technological challenges. Moreover, the 27 EU Member States have implemented the 1995 rules differently.

Therefore, the European Commission came up with the proposal for General Data Protection Regulation (GDPR). The adoption is aimed for 2014 and the regulation is planned to take the effect in 2016 after a transition period of 2 years.

GDPR is expected to give EU companies a competitive advantage globally as it has to replace 27 national regulations and to allow better control of personal data by setting data protection compliance regime with foreseen penalties. It will be applied if data controller or processor (organization) or the data subject (person) is based in the EU. Therefore, an impact of that regulation might be global. The regulation deals with issues of Data Protection Authority, responsibility and accountability of controller and processor, information and access of data, rectification and erasure, right to object and profiling, consent, data security, codes of conduct and certification, transfer of personal data to third countries or international organizations, supervision, cooperation, consistency, remedies, liabilities and sanctions.

Directive 2004/23/EC on setting standards of quality and safety for the donation, procurement, testing, processing, preservation, storage and distribution of human tissues and cells ${ }^{6}$

Directive deals with the donation, procurement, testing, processing, preservation, storage and distribution of human tissues and cells intended for human applications and of manufactured products derived from human tissues and cells intended for human applications. It also sets the obligation on Member States to ensure that all data, including genetic information, have been rendered anonymous so that neither donors nor recipients remain identifiable.

Directive 98/79/EC on in vitro diagnostic medical devices ${ }^{7}$ and proposal for Regulation on in vitro diagnostic medical devices ${ }^{8}$

Directive 98/79/EC deals with in vitro diagnostic medical devices (IVDs) that is products used in vitro for the examination of human specimens, including blood and tissue donations. It gives a possibility to the manufacturer to carry out the conformity assessment where devices do not constitute a direct risks to patients on their own.

European Commission recently came up with the proposal for Regulation on in vitro diagnostic

\footnotetext{
${ }^{4}$ http://eur-lex.europa.eu/LexUriServ/LexUriServ.do?uri=CELEX:31995L0046:EN:HTML

5 http://ec.europa.eu/justice/data-protection/document/review2012/com_2012_11_en.pdf

${ }^{6}$ http://eur-lex.europa.eu/LexUriServ/LexUriServ.do?uri=0J:L:2004:102:0048:0058:EN:PDF

${ }^{7}$ http://eur-lex.europa.eu/LexUriServ/LexUriServ.do?uri=CELEX:31998L0079:en:NOT

8 http://ec.europa.eu/health/medical-devices/files/revision_docs/proposal_2012_541_en.pdf
} 
medical devices. Regulation aims to strengthen certain key aspects of the IVD system, for instance: oversight by notified bodies, post-market safety, transparency, traceability and the overall regulatory management of the system. It also offers the opportunity to eliminate the gaps and weaknesses of the IVD Directive so as to ensure that IVDs used in the context of personalized medicine offer the appropriate level of safety and performance ${ }^{9}$.

Directive 2001/20/EC on the approximation of the laws, regulations and administrative provisions of the Member States relating to the implementation of good clinical practice in the conduct of clinical trials on medicinal products for human use ${ }^{10}$ and proposal for Regulation on clinical trials on medicinal products for human use ${ }^{11}$

Directive 2001/20/EC aims to ensure that clinical trials are conducted in compliance with good clinical practice (GCP).

European Commission recently came up with the proposal for Regulation on clinical trials on medicinal products for human use, which aims to boost clinical research in Europe by facilitating the conduct of clinical trials across several or all Member States. It also might facilitate clinical trials made by non-commercial sponsors. It sets the authorization procedure, simplified reporting procedures, more transparency on recruitment and results of the clinical trial. It also tries to expand the knowledge base and innovation by the obligation to publish the results in the database one year after the termination of each trial. ${ }^{12}$

\section{COUNCIL OF EUROPE CONVENTIONS}

Convention for the Protection of Human Rights and Dignity of the Human Being with regard to the Application of Biology and Medicine: Convention on Human Rights and Biomedicine ${ }^{13}$ (1997)

The Convention talks about several principles relating to Human Genome (Articles 11-14) prohibiting discrimination, selection of future child's sex and setting principles for intervention and genetic tests (i.e. genetic tests can be performed only for health purposes (directly and indirectly by scientific research) and subject to appropriate genetic counseling.

The Convention is extended by the Additional Protocol to the Convention on Human Rights and Biomedicine, concerning Genetic Testing for Health Purposes ${ }^{14}$ (2008) which applies to the tests carried out for health purposes, involving analysis of biological samples of human origin, and aiming specifically to identify the genetic characteristics of an individual inherited or acquired during early prenatal development. The Protocol deals with issues of genetic services (quality, clinical utility, individualized supervision), information and genetic counseling, consent (i.e. test may only be carried out if the individual has given free and informed consent), private life and right to information, genetic screening programs for health purposes and others.

\footnotetext{
9 http://ec.europa.eu/health/files/latest_news/2013-10_personalised_medicine_en.pdf

10 http://eur-lex.europa.eu/LexUriServ/LexUriServ.do?uri=0J:L:2001:121:0034:0044:en:PDF

11 http://ec.europa.eu/health/files/clinicaltrials/2012_07/proposal/2012_07_proposal_en.pdf

12 http://ec.europa.eu/health/files/latest_news/2013-10_personalised_medicine_en.pdf

$13 \mathrm{http} / / /$ conventions.coe.int/Treaty/en/Treaties/Html/164.htm

$14 \mathrm{http}: / /$ conventions.coe.int/Treaty/en/Treaties/Html/203.htm
} 